\title{
Optical Examination on Zinc Sulphide Nanoparticles for Photovoltaic Applications
}

\author{
P Sharmili, M S Revathy, S Rajesh, M Muthu Vinayagam, R Chokkalingam
}

\begin{abstract}
In this research work Zinc Sulphide nanoparticles are synthesized by co-precipitation method with zinc nitrate and sodium sulfide sources. The obtained particles are characterized to know its structure, crystalline pattern, crystalline size and other morphologies. The crystalline size of the material is calculated by Debye-Scherrer Formula. X-Ray Diffraction analysis, Scanning Electron Microscopy, Fourier Transform Analysis and $U V-V i s i b l e ~ s p e c t r u m$ analysis is performed to study the mentioned morphology and properties of the material synthesized. The central point of this research work is to study the behavior of Zinc sulfide nanoparticles for solar cell applications. Hence, luminescence property of the material is finally analyzed.
\end{abstract}

Keywords: About four key words or phrases in alphabetical order, separated by commas.

\section{INTRODUCTION}

Zinc sulphide has long been widely used in various fields of science and technology. However, interest in zinc sulphide is increased when it is known to develop new nanomaterials with unique properties. Zinc sulfide is a wide-band-gap semiconductor with a range of potential applications in optoelectronic devices [1]. The use of nano-materials as composites are gaining importance in science and technology owing to their superior properties like thermal, electrical conductivity, optical, photoluminescence and other novel attributes [2]. The $\mathrm{ZnS}$ material is an intrinsic semiconductor with wide band gap of about $3.54 \mathrm{eV}$ for cubic and $3.91 \mathrm{eV}$ for hexagonal form[3]. As a wide band gap semiconductor, $\mathrm{ZnS}$ is a promising candidate for replacement of toxic cadmium sulfide $(\mathrm{CdS})$ in the thin film solar cell application [4]. $\mathrm{ZnS}$ is an important material for diverse optoelectronic device applications such as sensors, electro-optic modulators, n-type window layers in photovoltaic cells, and electroluminescent devices.

Revised Manuscript Received on July 22, 2019

* Correspondence Author

P Sharmili, Department of Physics, Kalasalingam Academy of Research and Education, Krishnankoil, Tamil Nadu, India. Email: sharmilipandian.s@gmail.com

M S Revathy, Department of Physics, Kalasalingam Academy of Research and Education, Krishnankoil, Tamil Nadu, India. Email: revathy.ms@klu.ac.in.

S Rajesh, Department of Mechanical Engineering, Kalasalingam Academy of Research and Education, Krishnankoil, Tamil Nadu, India. Email: s.rajesh@klu.ac.in

R Chokkalingam*, Department of Physics, Kalasalingam Academy of Research and Education, Krishnankoil, Tamil Nadu, India. Email: chokka84@gmail.com

M Mahendran, Department of Physics, Thiagarajar College of Engineering, Madurai, Tamil Nadu, India. Email: manickam-mahendran@tce.edu
Though we have enormous types of solar cells everything does not possess energy efficiency. Still, solar cells possess high heat absorbance since energy from sunlight heats up the panel. Increase in the thermal energy decreases the efficiency of solar cells. Investigation on Photovoltaics (PV) attracted many researchers since their growing demand. Regarding efficiency of solar cells, the aim for detection and conversion of solar light into electrical energy at the atomic level was investigated broadly $[5,6]$. Window materials layers have also been alternatively used as an effort to decrease the loss of absorption in the window layer [7]. The highest reported values of power conversion efficiencies (PCEs) for pure CZTS, pure CZTSe and their mixture based solar cells have reached $8.4,12.6$ and $11.6 \%$, respectively [8,9]. The maximum efficiency recorded for copper indium sulfide (CuInS2) thin-film based solar cell is $12.5 \%$ and in the case of using $\mathrm{ZnS}$ the best efficiency of about $7.8 \%$, was recorded for the cell structure $\mathrm{Mo} / \mathrm{CuInS} 2 / \mathrm{ZnS} / \mathrm{ZnO}$ [10].

In this study, to understand the importance of absorbance and luminescent parameter for $\mathrm{ZnS}$ materials using simple synthesis technique. The main objective of this work is to investigate the photoluminescent and thermoluminescent characteristics of $\mathrm{ZnS}$ experimentally.

\section{EXPERIMENTAL WORK}

The precursors are zinc nitrate $\mathrm{Zn}(\mathrm{NO} 3) 2$ for Zinc source and Sodium sulfide Na2S for Sulphide source. 0.1M of Zinc Acetate was prepared in ethanol and $0.1 \mathrm{M}$ sodium sulfide solution was taken in a burette. Under controlled addition of sodium sulfide drops to Zinc acetate solution and constant stirring for 12 hours, a white precipitate was obtained. The precipitate was centrifuged and sonicated using ultrasonic cleaner and washed 4 to 5 times with deionized water. The precipitate was dried in muffle furnace at $200^{\circ} \mathrm{C}$ for 4 hours Then, the obtained powder sample was stored for further characterization studies. The procedure was repeated for the concentration of $\mathrm{ZnS} 0.2 \mathrm{M}$ till1M.

\section{RESULTS AND DISCUSSION}

\section{A. XRD Pattern of ZnS Nanoparticles:}

The arrangement of atoms in a crystal plays a vital role in defining the properties of a material. Almost all the properties depend on the structure of a material. For example, Diamond and Graphite are allotropes of carbon.

As we know diamond is the strongest material whereas graphite is brittle and we can easily break the graphite material.

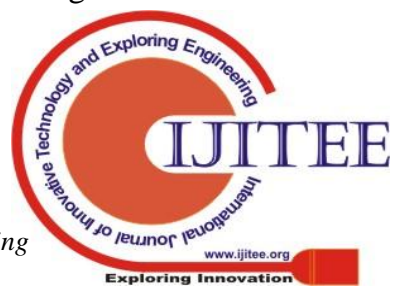


The structure of $\mathrm{ZnS}$ Nano particles were characterized by using X-Ray Diffractometer. The results obtained were compared with JCPDS data and peaks were indexed as per the JCPDS profile.

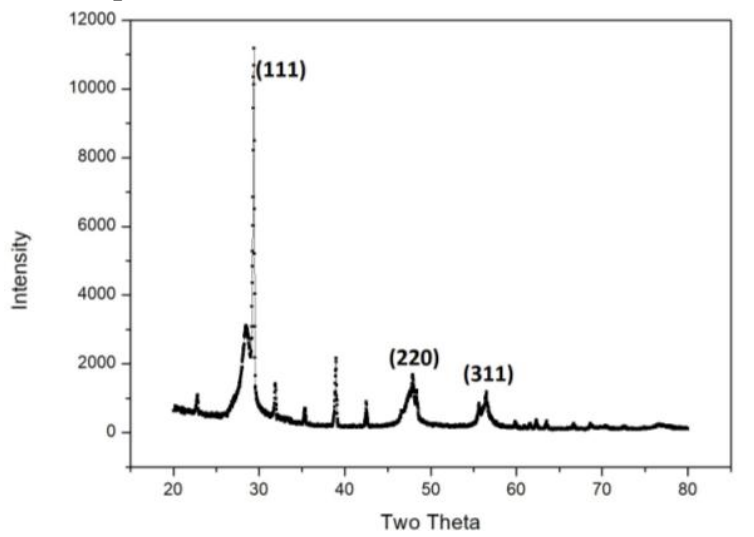

Fig 1. XRD pattern for $0.1 \mathrm{M}$ concertation $\mathrm{ZnS}$

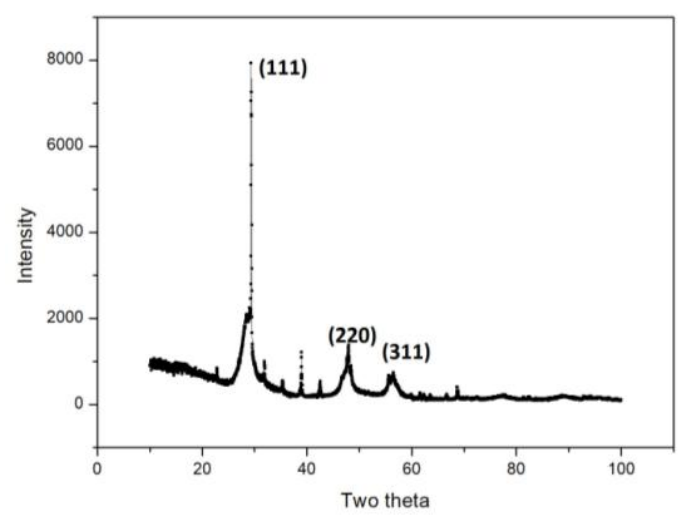

Fig 1. XRD pattern for $0.2 \mathrm{M}$ concertation $\mathrm{ZnS}$

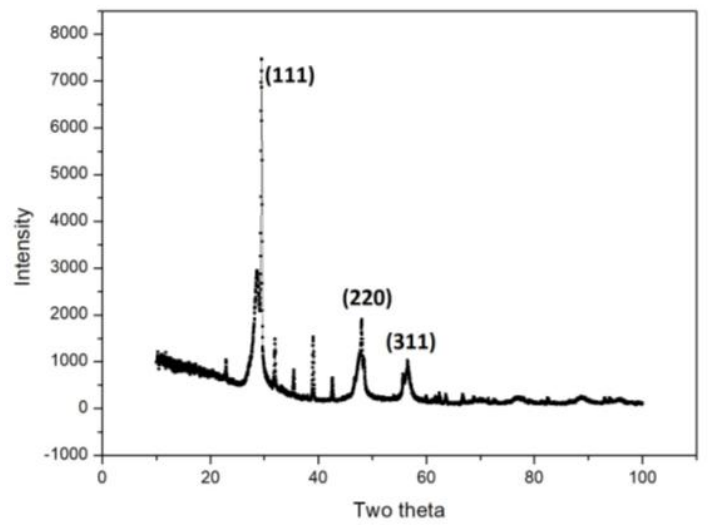

Fig 1. XRD pattern for $0.3 \mathrm{M}$ concertation $\mathrm{ZnS}$

The crystalline nature of the prepared nanosized $\mathrm{ZnS}$ powder is evident from the X-ray diffraction pattern Fig. 1. The indexed peaks at $2 \theta=19.409^{\circ}, 2 \theta=27.786^{\circ}, 2 \theta=$ $33.053^{\circ}$ and $2 \theta=33.521^{\circ}$ corresponding to the (111), (220) and (222) planes, respectively, matches with the reported value (JCPDS card, No. 5-0566). The peaks are identified as spherically cubic (blend) structure. The broad feature of the peaks indicates the crystal size is in nanometers range. The isostructural phase may be caused by the presence of substitutional impurities of similar atomic size but differing atomic number that give rise to deviation in intensity.

XRD patterns for $\mathrm{ZnS}$ nanoparticles synthesized in $0.2 \mathrm{M}$ concentration is shown in Fig 2. The X-ray pattern of $\mathrm{ZnS}$ nanoparticles shows sharper and stronger diffraction peaks at 25.879, 27.958, 31.449, 32.585, 33.324 and 33.324 units. These peaks correspond to cubic lattice structure of $\mathrm{ZnS}$ (Zinc blende) and assigned the planes (111), (220), (311). The different peaks were indicating high purity and well crystalline form $\mathrm{ZnS}$. The presence of broad peaks in the XRD pattern implies presence of smaller particles. The d-spacing values are in good agreement with JCPDS No.77-2100.

Zinc blend and wurtzite are the two most popular structural configuration of $\mathrm{ZnS}$. Due to size effect the peaks broaden and then widths become larger as the crystal becomes smaller. Ghosh et al [11] reported that the broadening of the peak may also occur due to micro strains of the crystal structure arising from defects like dislocation and twinning etc. There is a slight shift in the peak due to internal stress.

\section{B. FTIR Analysis:}

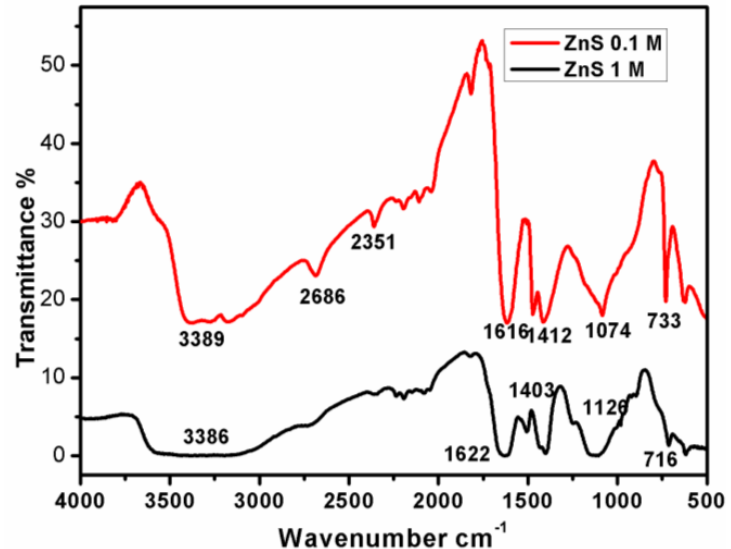

Fig 4. FTIR pattern for $\mathrm{ZnS}$ with $0.1 \mathrm{M}$ and $1 \mathrm{M}$ concentration

The FTIR spectrum of $\mathrm{ZnS}$ nanoparticles as shown in Fig 4 clearly indicates the characteristic functional groups which confirm the nanoscale properties of $\mathrm{ZnS}$ synthesized. The different peaks obtained at various points were compared with standard FTIR spectrum. Accordingly, the small peak observed at $3,448 \mathrm{~cm}-1$ and corresponds to Hydrogenbonded $\mathrm{O}-\mathrm{H}$ stretch bending vibration of phenols and alcohol band; the set of small peaks present at 2,926 cm-1 and 2,856 $\mathrm{cm}-1$ indicates the presence of $\mathrm{C}-\mathrm{H}$ Stretch off $\mathrm{C}=\mathrm{O}$ vibration of $\mathrm{C}-\mathrm{O}$ and a small peak observed at 1,720 cm-1 represents $\mathrm{C}=\mathrm{O}$ stretch correspond to Carboxylic acids band; a strong peak at 1,622 $\mathrm{cm}-1$ represent $\mathrm{C}=\mathrm{O}$ Stretch corresponds to Amide band; A small peak at $1,562 \mathrm{~cm}-1$ represent $\mathrm{N}-\mathrm{H}$ stretch corresponds to amide; a small peak observed at 1,543 $\mathrm{cm}-1$ represent $\mathrm{N}-\mathrm{H}$ bend is the characteristic of AminesSecondary band; a small peak present at $1,517 \mathrm{~cm}-1$ corresponds to $\mathrm{N}-\mathrm{O}$ asymmetric stretch nitro compounds;

a small peak corresponds to $1,460 \mathrm{~cm}-1$ and $1,421 \mathrm{~cm}-1$ are $\mathrm{C}-\mathrm{H}$ bend and alkanes bond respectively; a small peak observed at $1,398 \mathrm{~cm}-1$ indicate $\mathrm{N}=\mathrm{O}$ bend; a small peak observed at $1,369 \mathrm{~cm}-1$ indicates $\mathrm{C}-\mathrm{H}$ rock 
alkanes; a broad peak observed at $9,16 \mathrm{~cm}-1$ corresponds to $\mathrm{O}-\mathrm{H}$ bend carboxylic acids. FTIR results of the present study on $\mathrm{ZnS}$ nanoparticles are in conformity with FTIR spectrum obtained by other research works for $\mathrm{ZnS}$ nanoparticles synthesized. Their spectrum indicates the presence of several strong peaks represents $\mathrm{C}-\mathrm{OH}$ vibrations $(1,088 \mathrm{~cm}-1$ and $1,111 \mathrm{~cm}-1), \mathrm{O}-\mathrm{H}$ bending vibration $(1,404 \mathrm{~cm}-1), \mathrm{O}=\mathrm{C}=\mathrm{O}$ stretching $(2,358 \mathrm{~cm}-1)$, phenol $\mathrm{CO}-\mathrm{H}$ stretching $(3,527$ cm-1), N-H stretching $(3,482 \mathrm{~cm}-1)$, alkenyl C-H stretch $(3,010 \mathrm{~cm}-1)$ and amide $\mathrm{N}-\mathrm{H}$ stretching $(3,742 \mathrm{~cm}-1)$.

The peak at $405 \mathrm{~cm}-1$ is the characteristic absorption of $\mathrm{Zn}-\mathrm{S}$ bond. Other weak absorption peaks which corresponding to the sodium sulfate in the materials. This result show suitable agreement with previous works.

\section{Microstructure of $\mathrm{ZnS}$ Nano Particles:}

The Microstructure of the $\mathrm{ZnS}$ Nano particles were Analysed using Scanning Electron Microscope (ZEISS). The SEM images showed that the samples were composed of agglomerated and isolated particles and it reveals that small particles aggregate into secondary particles because of their extremely small dimension and high surface energy. Therefore, the diameter and the size distribution of the nanoparticles are difficult to be determined precisely by simply viewing the SEM images.
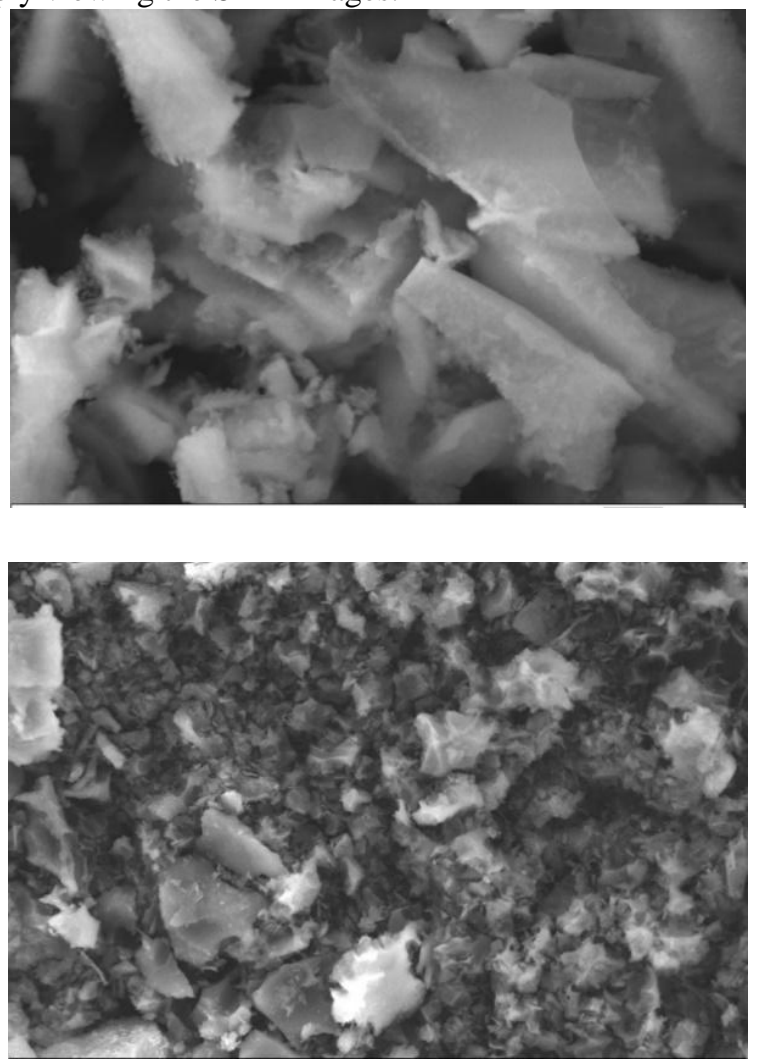

Fig 5: SEM structure of $\mathrm{ZnS}$ nanoparticles

\section{Analysis from Ultra Violet - Visible Spectroscopy:}

UV-Vis absorption spectra of various molar concentrations of $\mathrm{ZnS}$ materials were observed in SHIMADZU UV-1900 instrument with wavelength range from 200 to $900 \mathrm{~nm}$. The solvent was diluted in deionized water. The maximum absorption peaks were observed at around $325 \mathrm{~nm}$. The UV-Vis absorption spectra are shown in fig 6. UV-Visible spectra are a best supporting tool to identify and to recognize the optical absorption actions of semiconductor nanoparticles. The optical absorption spectrum of $\mathrm{ZnS}$ NPs is shown in fig 6. An absorption peak was observed in $325 \mathrm{~nm}$ for as synthesized $\mathrm{ZnS}$ nanoparticles and was in good agreement with the reported articles.

From the UV plot, the energy band gap is measured with the help of Tauc relation, The graph is plotted between (hv) vs $(\alpha h v)^{2}$

Where,

$$
\begin{gathered}
\alpha=\text { Absorption coefficient } \\
\mathrm{h}=\text { Plank constant }(\mathrm{js}) \\
\mathrm{A}=\text { Optical constant } \\
v=\text { Frequency }(\mathrm{Hz}) \\
\mathrm{Eg}=\text { Energy band gap }(\mathrm{eV})
\end{gathered}
$$

From the tauc plot, the band gap of various concentration of $\mathrm{ZnS}$ materials were determined and the values are occurred in $3.1 \mathrm{eV}$ to $3.6 \mathrm{eV}$.

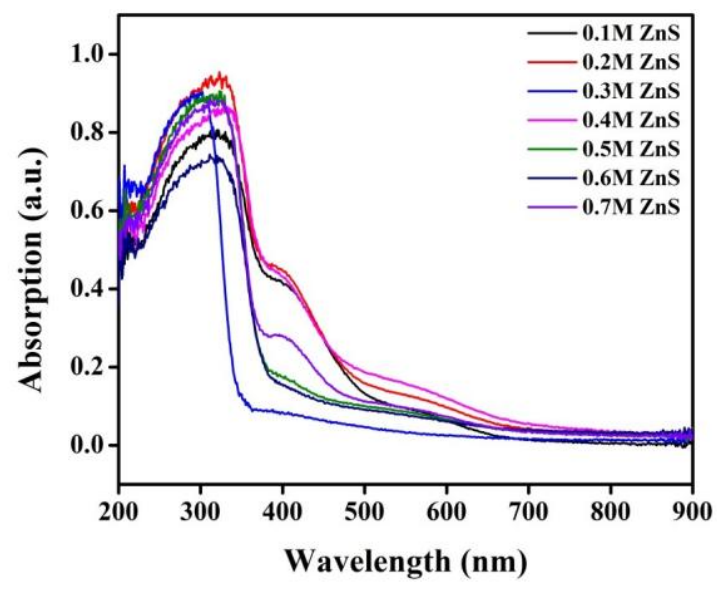

Fig. 6 UV-Vis absorption spectra of $\mathrm{ZnS}$

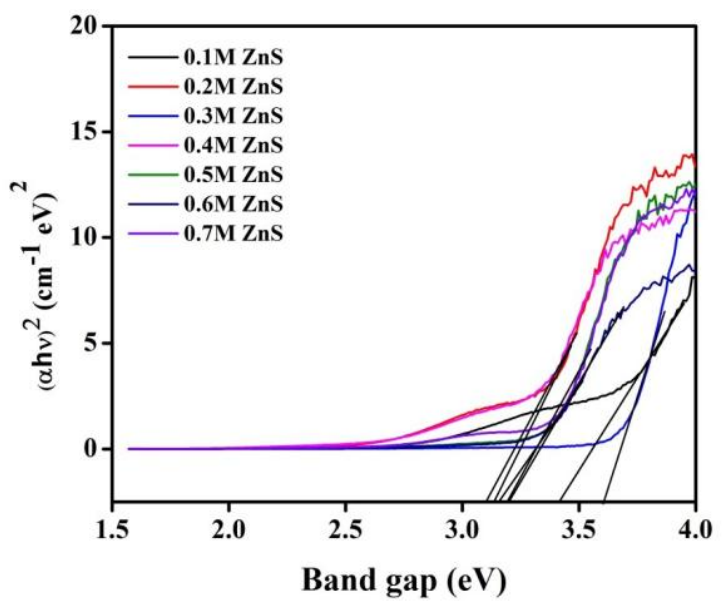

Fig.7: Band gap of $\mathrm{ZnS}$

\section{PHOTOLUMINESCENCE}

\section{Published By:}

Blue Eyes Intelligence Engineering \& Sciences Publication 


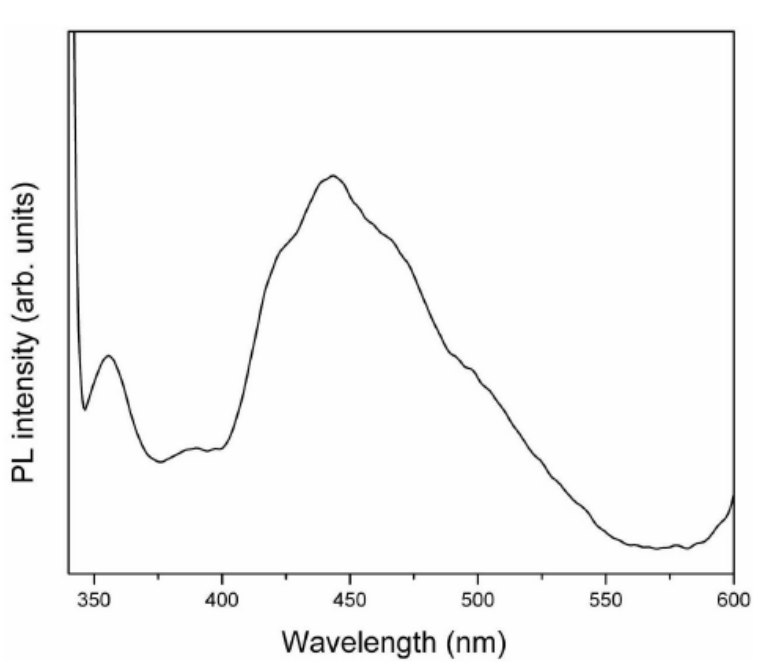

Fig 8: Photoluminescent spectrum of $\mathrm{ZnS}$

The PL spectrum of the as-synthesized ZnS NPs is shown in fig 8. From the data it is evident that there is a strong emission band at about $448 \mathrm{~nm}$ and this could be due to the emission of blue fluorescence attributed to the recombination that has been taken place between the shallow electron trap states (i.e) $S$ vacancy - the VB(valence band) and $\mathrm{CB}$ (conduction band) $-\mathrm{Zn}$ vacancy trap, respectively.

\section{CONCLUSION}

ZnS NPs were successfully synthesized by coprecipitation method. The calculated particle size from Debye-Scherrer formula was approximately $10 \mathrm{~nm}$. The obtained structure well coincides with the JCPDS file and the structure is confirmed that Zinc Cube blended. A morphological study of SEM shows rock-like structure with agglomeration. The FTIR studies inferred the presence of stretching and bending assignments. The inference from UV absorption of $325 \mathrm{~nm}$ clearly indicates the blue shift. The investigation on photoluminescence evidenced that there is an emission at 448 $\mathrm{nm}$. These results affirm that the synthesized material can be used in photovoltaic technology especially as a buffer layer in solar cells.

\section{REFERENCES}

1. Rui-Wei You, Yen-Pei Fu,, "Zinc Sulfide Buffer Layer for CIGS Solar Cells Prepared by Chemical Bath Deposition," Adv. Technol. Innov, vol. 2(3), pp. $95-98,2016$.

2. P. Asha, M. Rajeswari and B. Bindhu, "Zinc sulfide nanoparticles: processing, properties and applications: an overview", J Chem Pharm Sci, Vol.9(4), pp. 2047-2052, 2016.

3. Salim Oudah Mezan, Abdullah Hasan Jabbar, Maytham Qabel Hamzah, Alaa Nihad Tuama, Nabeel Naeem Hasan, Mohd Arif Agam, "Synthesis and Characterization of Zinc Sulphide $(\mathrm{ZnS})$ Thin Film Nanoparticle for Optical Properties," J. Glob. Pharm. Technol., vol. 10(07), pp. 369-373, 2018.

4. Mahdi H. Suhail, Omed Gh. Abdullah, Raoof A. Ahmed, Shujahadeen B. Aziz, "Photovoltaic Properties of Doped Zinc Sulfide/n-Si Heterojunction Thin Films", Int. J. Electrochem. Sci., vol. 13, pp. 1472 - 1483, (2018).

5. V.B. Pujari, D.J. Dhage, and L.P. Deshmukh, Photo-voltaic Study of Hg Doped ZnS Thin Films, Inter. J. of Appl. Innov. Eng. Man., vol. 2(2), pp. 275, 2013.

6. E.U. Masumdar, L.P. Deshmukh, S.H. Mane, V.S. Karande, V.B. Pujari, and P.N. Bhosale, CdSe : Sb electrode for photoelectrochemical applications, J. Mater. Sci. Mater. Electron., vol. 14, pp.43, (2003).
7. S. Hossain, N. Amin, and T. Razykov, Prospects of back contacts with back surface fields in high efficiency ZnxCd1-xs /CdTe solar cells from numerical modeling, Chalcogenide Lett., vol.8, pp.187, (2011).

8. M.A. Akram, S. Javed, M. Islam, M. Mujahid, and A. Safdar, Arrays of CZTS sensitized $\mathrm{ZnO} / \mathrm{ZnS}$ and $\mathrm{ZnO} / \mathrm{ZnSe}$ core/shell nanorods for liquid junction nanowire solar cells, Sol. Energ. Mater. Sol. Cells, vol. 146,pp.121,(2016).

9. M. Guo, X. Zhu, and H. Li, Comparative study of $\mathrm{Cu} 2 \mathrm{ZnSnS} 4$ thin film solar cells fabricated by direct current and pulse reverse co-electrodeposition, J. Alloy. Compd., vol. 657, pp.336, (2016).

10. C. Calderon, J.S. Oyola, P. Bartolo-Perez, and G. Gordillo, Studies in CuInS2 based solar cells, including $\mathrm{ZnS}$ and In2S3 buffer layers, Mater. Sci. Semicon. Proc., vol. 16, pp. 1382, (2013).

11. M.K.Ghosh, S.Anand, R.P.Das, Effect of dissolved impurities during ammonia leaching of pure zinc sulphide, Hydrometallurgy, Vol.22(1-2), pp.207-221, 1989.

\section{AUTHORS PROFILE}

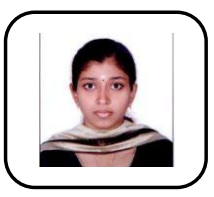

Sharmili Pandian, received her Bachelor degree and Master Degree in Physics. Now pursuing her Doctorate in field of Magnetorheological Fluid.

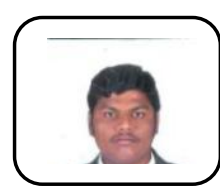

Dr. R. Chokkalingam, is an Associate Professor. He received his Doctorate in Physics in field of Actuators Applications with Shape Memory Alloys..

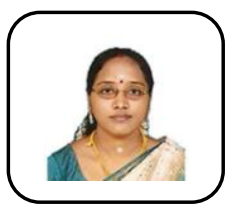

Dr. M. S. Revathy, is a Ph.D. holder currently pursuing in Kalasalingam Academy of Research and Education, Tamil Nadu, India. 